\title{
MANCHA FISIOLOGICA E PRODUTIVIDADE DO MAMÃO TAINUNG 01: EFEITO DA LÂMINA DE IRRIGAÇÃO E COBERTURA DO SOLO
}

\author{
Skin freckles and yield components of papaya Tainung 01: effect of irrigation \\ depths and soil coverings
}

\author{
Aroldo Gomes Filho ${ }^{1}$, Jurandi Gonçalves de Oliveira ${ }^{2}$, Alexandre Pio Viana ${ }^{3}$, Messias Gonzaga Pereira ${ }^{4}$
}

\begin{abstract}
RESUMO
Nesse experimento avaliou-se o efeito de diferentes lâminas de irrigação e coberturas do solo, sobre a incidência da mancha fisiológica do mamão e aspectos de produção do mamão cv. Tainung 01, no período de dezembro de 2003 a novembro de 2004. Utilizou-se delineamento em blocos casualizados em esquema fatorial. Quando as interações foram significativas desdobraram-se as mesmas e efetuaram-se as comparações das médias, via Teste Tukey. Os resultados encontrados demonstram uma alta correlação entre os fatores estudados e a época de colheita. Com relação à mancha fisiológica do mamoeiro confirmou-se o aspecto sazonal de incidência, sendo que, a cv. Tainung 01 apresentou a maior incidência do distúrbio, nos meses de setembro e outubro. Com relação às coberturas de solo, a cobertura morta se mostrou promissora para as variáveis de produção, ao contrário da cobertura verde com a leguminosa Arachis pintoi, pois a mesma competiu com o mamoeiro acarretando, assim, redução na produtividade.
\end{abstract}

Termos para indexação: Carica papaya L., distúrbio fisiológico, manejo alternativo, manejo do solo e da irrigação.

\section{ABSTRACT}

In this experiment one evaluated the effect of different irrigation dosages and soil coverings in skin freckles aspects in yield components of the papaya cv. Tainung 01 in the period from December 2003 to November 2004. It was used a randomized complete block design, with a three replications, in a factorial scheme. When the interactions were significant the analysis was partitioned and the means were compared by the Tukey Test for each factor. The results found demonstrated high correlation between the variable studied and the harvest season. With relation to the skin freckles the seasonal aspect of incidence was confirmed, showing that for cv. Tainung 01 the major incidence of the disturbance was verified in September and October. With relation to the soil coverings, the mulching showed promising for the variables in yield, in contrast of the green covering with the leguminosae Arachis pintoi, because the last one competed with the papaya trees causing reduction in the yield components.

Index terms: Carica papaya L., physiological disturbance, alternative handling, soil and irrigation management.

(Recebido em 27 de outubro de 2006 e aprovado em 14 de fevereiro de 2008)

\section{INTRODUÇÃO}

O híbrido de mamoeiro (Carica papaya L.) Tainung 01 é, atualmente, a cultivar mais aceita entre os materiais provenientes do grupo formosa, entretanto, ela é bastante susceptível à ocorrência da mancha fisiológica do mamão (MFM), que prejudica a sua comercialização para o mercado externo.

Essa susceptibilidade à MFM tem acarretado prejuízos vultosos aos produtores, uma vez que os consumidores têm clara preferência pelo fruto com casca livre de manchas. Eloisa et al. (1994) e Kaiser et al. (1996), associam a ocorrência desse distúrbio com a ruptura dos laticíferos do fruto de mamão com conseqüente extravasamento do látex no tecido subepicárpico, fato esse que desencadearia o distúrbio. Essa ruptura dos laticíferos dos frutos poderia ocorrer em função de alterações bruscas na pressão interna desses condutores. Esse aumento na pressão interna dos laticíferos pode estar associado a fatores do ambiente, como o excesso de água no solo e alta umidade do ar (ELOISA et al., 1994) ou baixas temperaturas ou amplitudes térmicas, diárias, muito altas (DOWNTON, 1981).

\footnotetext{
'Engenheiro Agrônomo, Doutorando em Genética e Melhoramento de Plantas - Laboratório de Melhoramento Genético Vegetal/CCTA - Universidade Estadual do Norte Fluminense Darcy Ribeiro/UENF - Avenida Alberto Lamego, 2000 - Parque Califórnia - 28013-602 - Campos dos Goytacazes, RJ agomes@uenf.br

Engenheiro Agrônomo, Doutor em Biologia Vegetal, Professor Associado - Laboratório de Melhoramento Genético Vegetal/CCTA - Universidade Estadual do Norte Fluminense Darcy Ribeiro/UENF - Avenida Alberto Lamego, 2000 - Parque Califórnia - 28013-602 - Campos dos Goytacazes, RJ jugo@uenf.br

${ }^{3}$ Engenheiro Agrônomo, Doutor em Produção Vegetal, Professor Associado - Laboratório de Melhoramento Genético Vegetal/CCTA - Universidade Estadual do Norte Fluminense Darcy Ribeiro/UENF - Avenida Alberto Lamego, 2000 - Parque Califórnia - 28013-602 - Campos dos Goytacazes, RJ pirapora@uenf.br

${ }^{4}$ Engenheiro Agrônomo, PhD em Genética e Melhoramento, Professor Associado - Laboratório de Melhoramento Genético Vegetal/CCTA - Universidade Estadual do Norte Fluminense Darcy Ribeiro/UENF - Avenida Alberto Lamego, 2000 - Parque Califórnia - 28013-602 - Campos dos Goytacazes, RJ messias@uenf.br
} 
Embora o mercado interno ainda não seja tão exigente quanto à qualidade do fruto, os produtores têm se preocupado em melhorar a classificação e padronização do fruto comercializado, visando melhores preços e obtenção de novos mercados consumidores. Nesse intuito, fazem-se necessárias novas pesquisas e ações que visem minimizar esse distúrbio de ocorrência na cultura do mamoeiro.

Buscando a redução na ocorrência da MFM, preconizou-se o cultivo do mamão sobre diferentes lâminas de irrigação e coberturas do solo, com a finalidade de induzir variações menos bruscas na pressão interna exercidas nos laticíferos dos frutos, o que ocasionaria uma menor incidência do distúrbio fisiológico.

Objetivou-se, no presente trabalho, estudar a influência de diferentes lâminas de irrigação e coberturas do solo, nas variáveis de produtividade e incidência da MFM.

\section{MATERIAL E MÉTODOS}

Localização do experimento: $\mathrm{O}$ experimento foi desenvolvido durante doze meses, no período de dezembro/2003 a novembro/2004, na Empresa Caliman Agrícola S/A, na fazenda Romana, que está localizada no Município de Linhares na Região Norte do Estado do Espírito Santo, sendo integrante da microrregião 205, conhecida como Baixado Espírito Santense. A Fazenda Romana fica localizada na latitude $19^{\circ} 15^{\prime} \mathrm{S}$ e longitude de $39^{\circ} 51^{\prime} \mathrm{O}$.

Clima: O clima na microrregião 205 classifica-se como Awi na Escala de Koopen (tropical úmido), que se caracteriza por um verão úmido e um inverno seco. A precipitação média anual foi estimada em $1224,3 \mathrm{~mm}$, no período de 1975 a 1995 , temperatura média de $23{ }^{\circ} \mathrm{C}$ e umidade relativa do ar de 83,5\% (ROLIM et al., 1999). No período experimental, a precipitação média anual foi de $1.738,9 \mathrm{~mm}$, a temperatura média foi de $23,8^{\circ} \mathrm{C}$ e umidade relativa do ar de $84,3 \%$.

Solos: Os solos da Fazenda Romana são em sua maioria classificados como Podzólicos Vermelho Amarelo, textura argilo arenosa, fase floresta subperenifólia, relevo plano a suavemente ondulado (platôs litorâneos). Com relação à fertilidade, o solo possui as seguintes características: P, $39 \mathrm{mg} / \mathrm{dm}^{3} ; \mathrm{K}, 54 \mathrm{mg} / \mathrm{dm}^{3} ; \mathrm{S}, 4 \mathrm{mg} / \mathrm{dm}^{3}$; pH em água, 5,9; matéria orgânica, $3,6 \mathrm{dag} / \mathrm{Kg}$; relação $\mathrm{Ca} /$ $\mathrm{Mg}$ de 3,7; relação $\mathrm{Ca} / \mathrm{K}$ de 18,8 ; relação $\mathrm{Mg} / \mathrm{K}$ de 5,1 ; CTC efetiva, $3,4 \mathrm{cmol} / \mathrm{dm}^{3}$ e saturação de bases, $61,0 \%$. Além disso, o solo em questão apresenta-se totalmente sem restrições para o uso agrícola, não necessitando de práticas especiais de manejo para controle de erosão.
Material Vegetal: Foram utilizadas plantas com cerca de 18 meses de idade, da cultivar Tainung 01, em plena produção, dispostas em fileiras duplas (3,6 x 2,0 x 2,0 m) com irrigação por microaspersão, com faixa molhada contínua. As adubações de cobertura foram realizadas mensalmente, utilizando $160 \mathrm{~g}$ de sulfato de amônio e $80 \mathrm{~g}$ de cloreto de potássio. Com relação ao controle fitossanitário, durante o período experimental houve o monitoramento das principais pragas, sendo feitas pulverizações com fungicidas (controle de antracnose e pinta preta) e inseticidas (controle de ácaros e cochonilhas), quando necessário.

Tratamentos: Os tratamentos utilizados no experimento consistiram de três tipos de cobertura de solo: SN, sem cobertura - solo nu; CM, cobertura morta - lâmina ( $\cong 5 \mathrm{~cm}$ ) de capim colonião (Panicum maximum Jacq.), seco, picado e $\mathrm{CV}$, cobertura verde - amendoim forrageiro (Arachis pintoi Krapov. \& W.C.Greg), associadas a três lâminas de irrigação: $\mathrm{L}_{0}, 50 \%$ de $\mathrm{ET}_{0} ; \mathrm{L}_{1}, 100 \%$ de $\mathrm{ET}_{0}$ e $\mathrm{L}_{2}$, $150 \%$ de $\mathrm{ET}_{0}$, sendo a ETo determinada através da equação de Penman-Monteith (ALLEN et al., 1998).

Avaliações dos atributos de qualidade dos frutos: Os frutos foram colhidos no estádio dois de maturação (1/ 4 maduro), sendo avaliadas as seguintes características: 1) índice de ocorrência da MFM, através de análise subjetiva pela qual foram atribuídas notas para a incidência da MFM, de acordo com Oliveira et al. (2005) (nenhuma mancha, nota 0 ; muito baixa ocorrência, nota 1 ; baixa ocorrência, nota 2 ; média ocorrência, nota 3 ; alta ocorrência, nota 4 e finalmente, a nota 5 para muito alta ocorrência da mancha), sendo o método validado por Gomes Filho et al. (2006); 2) peso, médio, de seis frutos por parcela (amostragem) - obtido em balança semi-analítica; 3) número, médio, de frutos por planta - por contagem de todos os frutos de três plantas por parcela a cada três meses e 4) a produtividade - que foi determinada pela multiplicação do número, médio, de frutos por planta versus o peso médio de seis frutos. Os resultados da produtividade foram expressos em $\mathrm{T} \mathrm{ha}^{-1}$, considerando-se uma população média de 1.785 plantas por hectare.

Delineamento Experimental e Análise dos Resultados: O experimento foi instalado seguindo delineamento experimental em blocos casualizados com 3 repetições, em esquema de parcelas subdivididas, com o fator irrigação disposto na parcela e o fator cobertura disposto na subparcela, representando as três coberturas de solo e as três lâminas de irrigação, totalizando 27 parcelas com a unidade experimental composta de 3 plantas por parcela, utilizando-se 2 frutos por planta. 
Para a análise dos dados utilizou-se o programa Genes (CRUZ, 2001), sendo os resultados interpretados por meio de análises de variância com teste $\mathrm{F}$, a $5 \%$ de probabilidade, quando as interações foram significativas, as mesmas foram desdobradas, sendo as médias comparadas pelo teste Tukey, adotando-se $5 \%$ de probabilidade.

\section{RESULTADOS E DISCUSSÃO}

Os resultados da análise de variância para a variável MFM demonstrou que houve influência $(\mathrm{P}<0,05)$ conforme a época do ano em que os frutos foram colhidos, mas, não mostrou-se dependente da lâmina de irrigação ou mesmo da cobertura do solo, pelo teste de F, ao nível de 5\% de probabilidade (Quadro 1).

Pelos resultados da Figura 1, Observa-se que não houve resposta aos tratamentos no período de avaliação, muito provavelmente, devido aos altos índices de precipitação, ocorridos na região no respectivo período.

O alto índice de precipitação do período (Figura 2) promoveria, assim, igualdade no conteúdo de água nas diferentes parcelas (exceção nos meses de agosto e setembro), o que impossibilitou a avaliação da influência da lâmina de irrigação e coberturas de solo, na incidência da MFM. Entretanto, verifica-se um efeito sazonal na incidência do distúrbio, ao longo do ano. Os resultados demonstram que a maior incidência do distúrbio ocorreu nos meses de fevereiro, setembro e outubro. Campostrini et al. (2005), trabalhando com plantas de mamoeiro do grupo "Formosa" em um plantio comercial no município de São Francisco do Itabapoana - RJ verificaram, também, o efeito sazonal na variável MFM, onde encontrou-se uma maior incidência no mês de setembro.

Essa sazonalidade ao longo do ano foi observada também por Lima (2003) e Ueno et al. (2002), que relataram uma maior incidência da MFM nos meses de agosto e setembro. Os resultados apresentados nesse experimento foram similares aos observados por Lima (2003) e Ueno et al. (2002) no que se refere à maior incidência do distúrbio no mês de setembro. Os resultados aqui apresentados indicam, ainda, uma alta incidência da MFM, nos meses de outubro e fevereiro. No restante do ano, os valores do nível de ocorrência do distúrbio ficaram baixos, o que equivale à nota 2 , com alguns meses apresentando nota 1 , ou seja, muito baixa ocorrência de incidência do distúrbio. Isso demonstra que os tratamentos adotados pouco influenciaram na ocorrência do distúrbio nos meses citados.

A amplitude térmica registrada no período do experimento variou de $7,2{ }^{\circ} \mathrm{C}$ (janeiro) a $10,9{ }^{\circ} \mathrm{C}$ (setembro). Nos meses de maior ocorrência da MFM - setembro e outubro - verificam-se as maiores amplitudes térmicas, 10,9 ${ }^{\circ} \mathrm{C}$ e $9,1{ }^{\circ} \mathrm{C}$, respectivamente, o que poderia estar correlacionado com o distúrbio. Segundo Downton (1981) baixas temperaturas diurnas ou amplitudes térmicas diárias muito altas ocasionava uma maior pressão de turgescência

Quadro 1 - Resumo da análise de variância (ANOVA) para as avaliações realizadas no mamão cv. Tainung 01 durante o período de dez/03 a nov/04, sendo avaliadas as variáveis: Mancha Fisiológica do Mamão (MFM), Número de frutos por planta (NF), Peso do fruto (PF) e Produtividade (PROD).

\begin{tabular}{|c|c|c|c|c|c|}
\hline \multirow[t]{2}{*}{$\mathrm{FV}$} & \multirow[t]{2}{*}{ GL } & \multicolumn{4}{|c|}{ Quadrado Médio } \\
\hline & & MFM & $\mathrm{NF}$ & PF & PROD \\
\hline Bloco & 2 & 0.49 & 1.72 & 2.57 & 2.57 \\
\hline Período & 11 & $4.92 * *$ & $3.01^{\mathrm{ns}}$ & $53.19 * *$ & $6.75 *$ \\
\hline Lâmina & 2 & $2.01^{\mathrm{ns}}$ & $1.45^{\mathrm{ns}}$ & $3.73 *$ & $1.67^{\mathrm{ns}}$ \\
\hline Cobertura & 2 & $1.74^{\mathrm{ns}}$ & $2.58^{\mathrm{ns}}$ & $5.32 *$ & $3.85 *$ \\
\hline Per*Lam & 22 & $2.27^{\mathrm{ns}}$ & $1.44^{\mathrm{ns}}$ & $2.18^{\mathrm{ns}}$ & $1.24^{\mathrm{ns}}$ \\
\hline Per*Cober & 22 & $1.93^{\mathrm{ns}}$ & $0.93^{\mathrm{ns}}$ & $0.89^{\mathrm{ns}}$ & $0.93^{\mathrm{ns}}$ \\
\hline Lam*Cober & 4 & $2.11^{\mathrm{ns}}$ & $0.91^{\mathrm{ns}}$ & $3.08^{\mathrm{ns}}$ & $0.87^{\text {ns }}$ \\
\hline Per*Lam*Cober & 44 & $1.61^{\mathrm{ns}}$ & $0.57^{\text {ns }}$ & $1.36^{\mathrm{ns}}$ & $0.47^{\mathrm{ns}}$ \\
\hline Média & & 1.81 & 14.11 & 1536.02 & 39.39 \\
\hline $\mathrm{CV}(\%)$ & & 35.43 & 37.53 & 12.32 & 45.38 \\
\hline
\end{tabular}

ns - Não significativo a $5 \%$, pelo teste Tukey.

*Significativo a $5 \%$, pelo teste Tukey.

**Significativo a $1 \%$, pelo teste Tukey. 


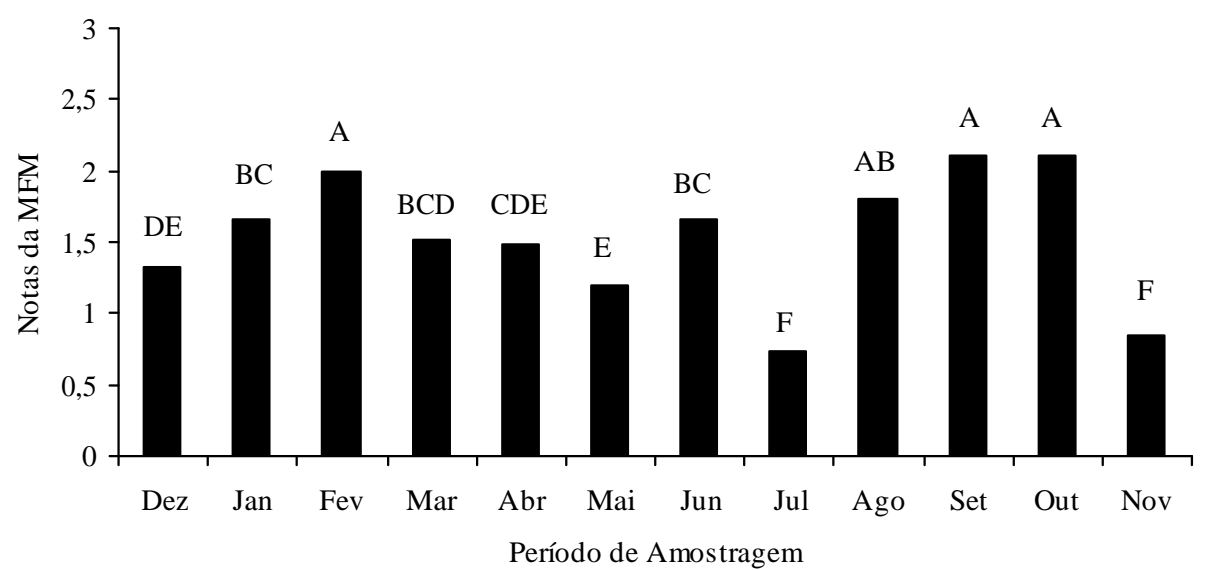

Figura 1 - Nível de ocorrência da Mancha Fisiológica do Mamão (MFM) em frutos da cv. Tainung 01, durante o período de dez/03 a nov/04.

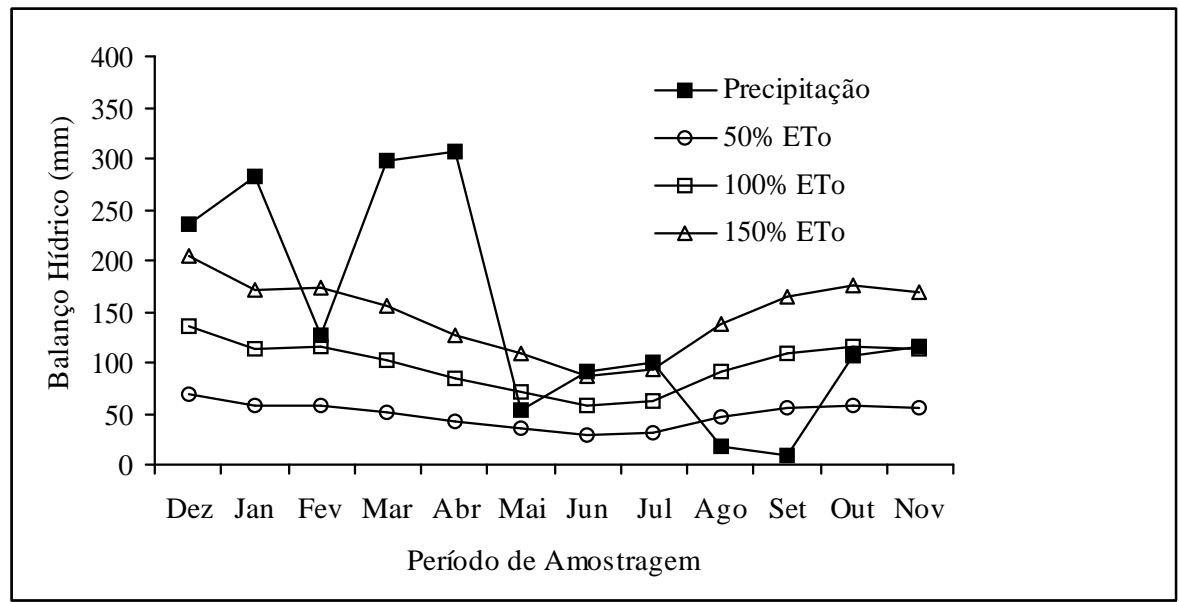

Figura 2 - Balanço hídrico durante o período de dez/03 a nov/04, em função da precipitação e dos tratamentos aplicados.

nos vasos laticíferos de Nerium oleander L. Segundo esse autor, o aumento na pressão dentro dos vasos foi duas vezes maior, quando da ocorrência das baixas temperaturas atmosféricas, em relação à época com elevadas temperaturas do ar. Nos meses de agosto a outubro registrou-se as maiores amplitudes térmicas, diárias, condições essas, segundo Downton (1981), propicias para uma maior pressão de turgescência nos vasos laticíferos do fruto. É provável que a maior pressão nos vasos laticíferos esteja relacionada à maior ocorrência da MFM no respectivo período, o que comprovaria uma estreita correlação entre a amplitude térmica diária e a incidência da MFM.

A variável número de frutos (NF) não sofreu influência $(\mathrm{P}<0,05)$ do período do ano em que os frutos foram colhidos, além dos resultados, também, não mostrarem influenciados pela alteração do manejo da cultura, pois essa característica não foi significativa pelo Teste F a 5\% de probabilidade (Quadro 1).

Os resultados obtidos para a variável número de frutos (Tabela 1) indicam que está variável não foi alterada pelos tratamentos, sendo portanto, constante ao longo do ano com valor médio de 14 frutos por planta. Silva et al. (2001) trabalhando com diferentes lâminas de irrigação no mamoeiro, encontraram influência deste tratamento no número de frutos, sendo que estes autores registraram valores, médios, de 30 frutos por planta utilizando uma lâmina de irrigação de $120 \%$ da ETo com um turno de rega de 2 dias. No trabalho em questão, o turno de rega foi diário. 
Tabela 1 - Estimativa do peso médio de frutos (PF), do número médio de frutos (NF) e da produtividade em $\mathrm{T}$ ha-1 (PRODUT) da cv. Tainung 01, durante o período de dez/03 a set/04, em função das lâminas de irrigação e coberturas do solo aplicadas: Cobertura morta (CM), Cobertura verde (CV) e Solo nu (SN).

\begin{tabular}{|c|c|c|c|c|c|c|c|}
\hline \multirow[b]{2}{*}{ Variável } & \multirow[b]{2}{*}{ Lâminas } & \multirow[b]{2}{*}{ Coberturas } & \multicolumn{4}{|c|}{ Épocas } & \\
\hline & & & Dez & Mar & Jun & Set & \\
\hline \multirow{9}{*}{$\mathrm{PF}$} & \multirow{3}{*}{$50 \%$ Eto } & $\mathrm{CM}$ & $1310,35 \mathrm{Ba}$ & $1463,00 \mathrm{Ba}$ & $2016,62 \mathrm{Aa}$ & $1493,51 \mathrm{Ba}$ & \\
\hline & & $\mathrm{CV}$ & $1005,20 \mathrm{Ca}$ & $1529,27 \mathrm{Ba}$ & $1887,13 \mathrm{Aa}$ & $1367,38 \mathrm{Ba}$ & \\
\hline & & SN & $990,25 \mathrm{Ca}$ & $1478,27 \mathrm{Ba}$ & $1776,49 \mathrm{Aa}$ & $774,50 \mathrm{Cb}$ & \\
\hline & \multirow{3}{*}{$100 \%$ Eto } & $\mathrm{CM}$ & $1497,13 \mathrm{Ca}$ & $1585,18 \mathrm{BCa}$ & $1873,55 \mathrm{Aa}$ & $1734,37 \mathrm{ABa}$ & \\
\hline & & $\mathrm{CV}$ & $1177,47 \mathrm{Ca}$ & $1470,18 \mathrm{Ba}$ & $1821,46 \mathrm{Aa}$ & $1434,84 \mathrm{Ba}$ & \\
\hline & & SN & $1170,71 \mathrm{Ca}$ & $1485,20 \mathrm{Ba}$ & 1738,62 Аа & $1579,11 \mathrm{ABa}$ & \\
\hline & \multirow{3}{*}{$150 \%$ Eto } & $\mathrm{CM}$ & $1052,07 \mathrm{Ca}$ & $1638,77 \mathrm{Ba}$ & $1938,54 \mathrm{Aa}$ & 1496,31 Bab & \\
\hline & & $\mathrm{CV}$ & $1223,27 \mathrm{Ca}$ & $1497,86 \mathrm{Ba}$ & $1934,50 \mathrm{Aa}$ & $1159,96 \mathrm{Cb}$ & \\
\hline & & SN & $1236,23 \mathrm{Ba}$ & $1745,85 \mathrm{Aa}$ & $1806,28 \mathrm{Aa}$ & $1771,01 \mathrm{Aa}$ & \\
\hline \multirow[t]{2}{*}{$\mathrm{NF}^{1}$} & \multicolumn{2}{|l|}{ Média } & $16,00 \mathrm{~A}$ & $12,34 \mathrm{~A}$ & $15,24 \mathrm{~A}$ & $12,03 \mathrm{~A}$ & \\
\hline & & & & & & & Total $^{2}$ \\
\hline \multirow{3}{*}{ PRODUT } & \multirow{3}{*}{ Média } & $\mathrm{CM}$ & $37,12 \mathrm{Ba}$ & $34,68 \mathrm{Ba}$ & $62,50 \mathrm{Aa}$ & $41,36 \mathrm{ABa}$ & $175,66 \mathrm{~A}$ \\
\hline & & $\mathrm{CV}$ & $33,70 \mathrm{Aa}$ & $40,22 \mathrm{Aa}$ & $48,37 \mathrm{Aa}$ & $26,55 \mathrm{Aa}$ & $148,84 \mathrm{~B}$ \\
\hline & & SN & $33,01 \mathrm{Aa}$ & $27,40 \mathrm{Aa}$ & $42,69 \mathrm{Aa}$ & 34,99 Aa & $138,09 \mathrm{C}$ \\
\hline
\end{tabular}

As médias seguidas pela mesma letra, minúscula na coluna e maiúscula na linha não diferem entre si pelo Teste Tukey ao nível de 5\%de probabilidade. Os CVs (\%) das variáveis são respectivamente: 37,53 (NF); 12,32 (PF) e 45,38 (PRODUT).

1- Os valores de NF são relativos à média dos tratamentos aplicados.

2- Valores de produtividade total no período de avaliação.

Carvalho et al. (2004), trabalhando com diferentes coberturas de solo para a cv. Tainung 01, encontraram valores médios de número de frutos iguais a 18 , ou seja, superiores aos 14 encontrados nesse experimento.

A variável peso médio do fruto (PF) foi influenciada significativamente $(\mathrm{P}<0,05)$, para o período de colheita dos frutos, lâminas de irrigação e a cobertura do solo (Teste F, $5 \%$ de probabilidade).

Os resultados para as diferentes lâminas de irrigação (Tabela 1) demonstraram um padrão semelhante ao longo do período de avaliação, com a variável PF apresentando, de modo geral, os menores valores no período de dezembro. No mês de março o PF apresentou um acréscimo em seus valores, atingindo os maiores níveis no mês de junho, independentemente do tratamento aplicado. Esses resultados indicam, provavelmente, uma inibição no desenvolvimento do fruto ocasionado pelo excesso hídrico do período de dezembro, visto que no período seco do ano o PF apresentou um crescimento. Entretanto, esse menor valor obtido no período de dezembro, não desqualifica o fruto para a comercialização, visto que o mesmo ainda se encontra dentro do peso padrão para a cultivar que é de 800 a 1100g (COSTA \& PACOVA, 2003).

De modo geral os tratamentos em que se aplicaram a cobertura sobre o solo, com palha ou em associação com leguminosa, resultaram em maior PF, quando comparado ao tratamento com solo nu. Entre os dois tratamentos com cobertura de solo, o uso da cobertura morta demonstrou ser mais eficiente para aumentar o PF, principalmente no período do ano onde são registrados os níveis mais altos de PF, isto é, no mês de junho. Esses resultados fazem crer que os tratamentos que propiciem uma melhoria das características do solo, como os diferentes tipos de cobertura, acarretam em um maior peso do fruto.

Para as lâminas de 50 e $100 \%$ da ETo os tratamentos foram estatisticamente idênticos, entretanto, os menores 
valores de PF foram obtidos com o solo nu. Esses resultados podem ser explicados pela maior vulnerabilidade das plantas às condições climáticas (alta demanda evapotranspirométrica), se comparados aos tratamentos com coberturas de solo.

Para o tratamento com a lâmina de $150 \%$ da ETo associada às coberturas do solo, os maiores valores do PF foram obtidos no mês de junho enquanto que o tratamento com o solo nu mostrou superioridade nos meses de março, junho e setembro. Esses resultados encontrados sugerem que o solo nu, associado à lâmina de $150 \%$ da ETo, propiciou à cultura uma melhor aeração, se comparado ao solo coberto com palha ou amendoim forrageiro. A conseqüência disso, provavelmente, seria uma maior disponibilidade de nutrientes para essas plantas, comparadas àquelas que possuem o tratamento com coberturas de solo, uma vez que as mesmas estão em um solo com maior teor de umidade, isto é, menor aeração no ambiente das raízes, o que dificultaria a assimilação de nutrientes.

A variável produtividade do mamoeiro cv. Tainung variou $(\mathrm{P}<0,05)$, ao longo do período de colheita, além de mostrar-se dependente dos tratamentos com cobertura do solo (Teste F, $5 \%$ de probabilidade).

Nesse trabalho (tabela 1), não foram observadas diferenças marcantes de produtividade, entre as lâminas de irrigação aplicadas. Esses resultados não concordam com os encontrados por Almeida (2000) e Silva et al. (2001), que trabalhando com a cv. Sunrise Solo 72/12, verificaram um crescimento linear da produtividade com lâminas de até $120 \%$ e $160 \%$ de reposição da ETo, respectivamente.

De modo geral as coberturas do solo foram os tratamentos que propiciaram os maiores níveis de produtividade, pois os mesmos foram estatisticamente superiores quando comparados ao tratamento com solo $\mathrm{nu}$, atingindo valores acumulados de 175,66 e 148,84 $\mathrm{T}$ ha${ }^{1}$, respectivamente, para o tratamento com cobertura morta e cobertura verde. Esses resultados, em parte, confirmam a hipótese que a planta estaria sofrendo por estresse hídrico. Esses dados indicam que as coberturas de solo deveriam ser adotadas pelos produtores, pois nesse experimento encontraram-se os maiores valores de produtividade do mamão, com este tipo de tratamento.

Para o tratamento com cobertura morta, nas respectivas épocas de avaliações, os maiores valores de produtividade foram encontrados nos meses mais secos do ano, chegando a atingir valores de $62,50 \mathrm{~T} \mathrm{ha}^{-1}$ para o mês de junho, evidenciando assim, que a planta estaria sofrendo um menor estresse. Nos tratamentos com cobertura verde e solo nu, não houve diferenças significativas entre os períodos de avaliação, entretanto houve superioridade na produtividade para o tratamento com cobertura verde, pois, para todos os meses de avaliação as médias obtiveram valores superiores de produtividade, mesmo sendo estatisticamente idênticas, e quando comparada à produtividade anual dos tratamentos, à cobertura verde foi estatisticamente superior ao tratamento com o solo nu.

\section{CONCLUSÕES}

A MFM demonstrou uma sazonalidade de ocorrência ao longo do ano, com maior incidência do distúrbio no período de fevereiro, setembro e outubro. As variáveis de produção demonstraram resultados promissores com a utilização do tratamento com cobertura morta, pois esse tratamento propiciou um maior peso do fruto e produtividade para o mamão cv. Tainung 01 . O uso da cobertura verde mostrou superioridade quando comparado ao solo nu, para as variáveis peso do fruto e produtividade, entretanto, vale lembrar que essa leguminosa compete com a cultura, sendo então, uma alternativa, quando não se puder utilizar o tratamento com cobertura morta.

\section{AGRADECIMENTOS}

À Caliman Agrícola S/A pelo apoio técnico e logístico, à FAPERJ, CNPq e à FINEP pelo apoio financeiro.

\section{REFERÊNCIAS BIBLIOGRÁFICAS}

ALLEN, R. G.; PEREIRA, L. S.; RAES, D.; SMITH, M. Crop evapotranspiration: guidelines for computing crop water requirement. Roma: FAO, 1998. (Paper, 56).

ALMEIDA, F. T. Resposta do mamoeiro (Carica papaya L.) do grupo Solo a diferentes lâminas de irrigação no Norte Fluminense. 2000. Tese (Doutorado em Produção Vegetal) - Universidade Estadual do Norte Fluminense, Campos dos Goytacazes, 2000.

CAMPOSTRINI, E.; LIMA, H. C.; OLIVEIRA, J. G.; MONNERAT, P. H.; MARINHO, C. S. Teores de Ca e variáveis meteorológicas: relações com a incidência da mancha fisiológica do mamão no Norte fluminense. Bragantia, Campinas, v. 64, n. 4, p. 601-613, 2005.

CARVALHO, J. B.;LOPES, L. C.; ARAÚJO, A. M. A.;SOUZA, L. C.;CALDAS, R. C.;DALTRO JÚNIOR, C. A.;CARVALHO, L. L.; OLIVEIRA, A. A. R.; SANTOS, R. C. Leguminosas e seus efeitos sobre propriedades físicas do solo e produtividade do mamoeiro "Tainung 1". Revista Brasileira de Fruticultura, Jaboticabal, v. 26, n. 2, p. 335-338, 2004. 
COSTA, A. F. S.; PACOVA, B. E. V. Caracterização de cultivares, estratégias e perspectivas do melhoramento genético do mamoeiro. In: MARTINS, D. S.; COSTA, A. F. S. A cultura do mamoeiro: tecnologias de produção. Vitória, ES: [s.n.], 2003. p. 51-102.

CRUZ, C. D. Programa Genes: versão Windows: aplicativo computacional em genética e estatística. Viçosa: UFV, 2001. 648 p.

DOWNTON, W. J. S. Water relations of laticifers in Nerium oleander. Australian Journal of Plant Physiology, Melbourne, v. 8, p. 329-334, 1981.

ELOISA, M.; REYES, Q.; PAULL, R. E. Skin freckles on solo papaya fruit. Scientia Horticulturae, Amsterdam, v. 58, p. 31-39, 1994.

GOMES FILHO, A.; OLIVEIRA, J. G.; VIANA, A. P.; DAMASCENO JÚNIOR, P. C.; PEREIRA, M. G. Validação do método das notas para quantificação da incidência da mancha fisiológica do mamão através do uso de imagens digitais. Revista Brasileira de Fruticultura, Jaboticabal, v. 28 , n. 3, p. $365-368,2006$.

KAISER, C.; ALLAN, P.; WHITE, B. J.; DEHRMANN, F. M. Some morphological and physiological aspects of freckle on papaya (Carica papaya L.) fruit. Journal of South African Society Horticulturae Science, South African, v. 6, n. 1, p. 37-40, 1996.
LIMA, H. C. Relações entre o estado nutricional, as variáveis do clima e a incidência da Mancha Fisiológica do mamão (Carica papaya L.) no Norte Fluminense. 2003. Dissertação (Mestrado em Produção Vegetal) Universidade Estadual do Norte Fluminense, Campos dos Goytacazes, 2003.

OLIVEIRA, J. G.;PEREIRA, M. G.; MARTELLETO, L. A. P.; IDE, C. D. Mancha fisiológica do mamão: uma perspectiva de obtenção de material genético tolerante. Revista Brasileira de Fruticultura, Jaboticabal, v. 27, n. 3, p. 458461, 2005.

ROLIM, S. G.; COUTO, H. T. Z.; JESUS, R. M. Mortalidade e recrutamento de árvores na Floresta Atlântica de Linhares (ES). Scientia Forestalis, Piracicaba, v. 55, p. 49-69, 1999.

SILVA, J. G. F.;FERREIRA, P. A.; COSTA, L. C.; MELENDES, R. R. V.; CECOM, P. R. Efeitos de diferentes lâminas e frequiência de irrigação sobre a produtividade do mamoeiro (Carica papaya L.). Revista Brasileira de Fruticultura, Jaboticabal, v. 23, n. 3, p. 597-601, 2001.

UENO, B.; NEVES, E. F.; MACHADO FILHO, J. A.; YAMANISHI, O. K.; FAGUNDES, G. R.; CAMPOSTRINI, E. Mancha fisiológica em frutos de mamoeiro no oeste da Bahia: relatório de trabalho da parceria Universidade de Brasília com os produtores de mamão da Associação dos Irrigantes do Oeste da Bahia (AIBA). Brasília, DF: [s.n.], 2002. 109 p. 